\title{
Sobre intelecto geral, capital, comunicação e conhecimento: uma leitura dos Grundrisse
}

César Ricardo Siqueira Bolaño

Resumo: Este artigo representa a primeira parte de uma reflexão mais extensa que procurará esclarecer certos aspectos fundamentais das mudanças estruturais por que vem passando o capitalismo nas últimas décadas, vinculados ao que muitos autores vêm tratando sob o premonitório conceito de "intelecto geral", apresentado por Marx nos seus manuscritos de 1857-1858. Por limitações de espaço, limitar-me-ei aqui a apresentar as bases de minha interpretação do fenômeno, centrando-me na análise dos referidos trechos de Marx.

Palavras-chave: trabalho intelectual; capitalismo; economia do conhecimento.

\section{General intellect, capital, communication and knowledge: a reading of the Grundrisse}

\begin{abstract}
This article presents the first part of a more extended work, whose objective is to explain the fundamental aspects of the capitalist structural changes started in the last decades, linked to the premonitory concept of "general intellect", adopted by Marx in its 1857-1858 manuscripts. Many authors are recently discussing it but, in the limits of this paper I will discuss just the basis of my own interpretation, focused in the referred parts of Marx' Grundrisse.

1 Professor da Universidade Federal de Sergipe (UFS - Departamento de Economia) e do Programa de Pós-Graduação em Comunicação da Universidade de Brasília (UnB). Doutor em Economia pela UNICAMP. Bolsista de produtividade do CNPq. Diretor da revista EPTIC ON LINE (www.eptic.com.br) e presidente da União Latina de Economia Política da Informação, da Comunicação e da Cultura (ULEPICC). E-mail: bolaño@ufs.br.
\end{abstract}


BOLAÑO, C. Sobre intelecto geral, capital, comunicação e conhecimento: uma leitura...

Keywords: intellectual work; capitalism; knowledge economy.

JEL: P16

\section{Introdução}

Este artigo representa a primeira parte de uma reflexão mais extensa que procurará esclarecer certos aspectos fundamentais das mudanças estruturais por que vem passando o capitalismo nas últimas décadas, vinculados ao que muitos autores vêm tratando sob o premonitório conceito de "intelecto geral", apresentado por Marx nos seus manuscritos de 1857-1858. Pinçado nos Grundrisse, isolado do pensamento expresso, finalizado, visto e revisto pelo próprio autor, que se materializa na sua obra mais completa, esse interessante insight pode tornar-se enigmático e sujeito a mistificações. Entendido, ao contrário, na perspectiva da problemática da comunicação, da informação, da cultura e do conhecimento no capitalismo e da atual reestruturação produtiva, com base numa leitura sistemática d'O Capital, especialmente o Livro I, pode servir de alternativa à interpretação dada pelos teóricos do "capitalismo cognitivo", ou do "trabalho imaterial". ${ }^{2}$

O objetivo deste artigo é explicitar, primeiro, alguns conceitos desenvolvidos em outras ocasiões, que considero importantes para uma crítica da economia política do conhecimento, para, em seguida, retomar a leitura dos trechos célebres dos Grundrisse, explicitando seu interesse para o esclarecimento do que ocorre com o capitalismo a partir da reestruturação produtiva iniciada nos anos 70 do século passado. Ao contrário daquelas expressões bombásticas, citadas entre aspas no parágrafo anterior, prefiro considerar o problema na base do conceito marxiano de subsunção do trabalho. Intelectual. Nesse sentido, podese pensar que o movimento de "subsunção do trabalho intelectual", como preferi chamar o elemento essencial daquele processo (Bolaño 1995, 2002), representa a materialização histórica mais completa, na atualidade, da idéia de intelecto geral de Marx.

\section{Conceituação preliminar}

Antes de entrarmos no debate propriamente dito - para o qual, importantes contribuições críticas já foram feitas, fornecendo argumentos fortemente embasados e insights extremamente úteis -, vale resumir alguns conceitos que venho desenvolvendo a respeito, desde a minha

2 De autores como Negri, Hardt, Gorz, Lazzarato e outros que têm adquirido grande notoriedade no mundo acadêmico e nos movimentos sociais nos últimos anos, cujas idéias, por problemas de espaço, procurarei analisar em uma próxima oportunidade. 
definição de acumulação primitiva de conhecimento, na tese de doutoramento de 1993, que deu origem ao livro (Bolaño, 2000). A idéia é que a Revolução Industrial e, com ela, a instauração de um modo de produção especificamente capitalista dependem da constituição prévia, não apenas de uma acumulação primitiva de capital, realizada pelo grande capital mercantil do período imediatamente anterior, responsável pelos transbordamentos de capital para a produção, na manufatura, mas também de uma acumulação primitiva de conhecimento, que essa manufatura realizará, ao incorporar ao capital, o conhecimento dos processos de trabalho desenvolvidos pela classe trabalhadora artesanal ao longo dos séculos anteriores.

O período manufatureiro permite justamente essa apropriação pelo capital, do conhecimento anteriormente produzido pelo trabalho, conhecimento esse que, aliado ao desenvolvimento da mecânica e outras inovações decorrentes do trabalho intelectual científico, permitirá o desenvolvimento das máquinas ferramenta e a Revolução Industrial originária. A máquina ferramenta é o elemento central de todo o processo porque nela está plasmado o conhecimento previamente extraído da classe trabalhadora. O capital, na realidade, é revolucionário, na medida em que consegue, por um lado, romper a unidade prática entre trabalho manual e trabalho intelectual que existia no artesanato medieval, articulando, por outro, o segundo ao conhecimento científico que se incorpora, com isso, ao processo produtivo, sob a forma, ainda, da aplicação da mecânica na construção daquelas máquinas que materializam, assim, sob a forma de capital constante, uma parte tão crucial do conhecimento humano.

O capital é revolucionário, portanto, na medida em que rompe aquela unidade e, ao mesmo tempo, ao contrário do artesanato medieval, logra reunificar, no seu interior, e de acordo com seus interesses particulares, aquele conhecimento pragmático com o pensamento científico, aquele trabalho intelectual que se separara do manual na Grécia antiga e com ele nunca mais voltara a se reconciliar, como insiste Sohn-Rethel (1989). O trabalho deste último autor, aliás, será de suma importância para nós, mas, até aqui, todo o processo foi descrito por Marx nos chamados capítulos históricos do Livro Primeiro d'O Capital. De minha parte, chamei a esse processo de acumulação primitiva do conhecimento, para enfatizar aquilo que está absolutamente transparente no livro: o capital, compreendido como relação social, é poder econômico e conhecimento. É isso que permite a Sohn-Rethel criticar em Marx a falta, ao lado da crítica da economia política, de uma crítica da epistemologia, cujas linhas mestras ele próprio procurará definir no interior do materialismo dialético. 
Minha leitura de Sohn-Rethel, na verdade, é bem posterior à formulação do conceito de acumulação primitiva do conhecimento e posterior ainda à de subsunção do trabalho intelectual (Bolaño, 1995), definida para explicar o sentido último da Terceira Revolução Industrial, numa perspectiva estritamente marxiana. A incorporação de SohnRethel, posteriormente, permitirá voltar a propor a questão em outra dimensão (Bolaño, 2002), buscando os caminhos para resolver o problema que o autor formula de modo cristalino, mas, por pouco, não chega a dar solução completa, não tendo vivido o suficiente para conhecer as conseqüências da chamada Revolução Informacional (Lojkine, 1995), a saber, o problema das efetivas possibilidades de reconciliação entre trabalho manual e intelectual, para além do capital e, portanto, das possibilidades objetivas de superação do capitalismo e de todo sistema de dominação baseado na separação entre mão e cabeça. Sua crítica ao modelo soviético vai justamente nesse sentido.

Mais uma vez, a resposta passa por uma leitura cuidadosa do Livro Primeiro, acompanhado do Capítulo VI Inédito d'O Capital, em que Marx define o seu conceito de subsunção do trabalho no capital, articulado à discussão sobre a produtividade do trabalho, em que esclarece, ademais, en passant, embora não lhes desse muita importância, elementos fundamentais para a compreensão da subsunção do trabalho intelectual e cultural, citando especificamente o caso da cantora, do médico e do professor. Não cabe entrar aqui na discussão desse importante trabalho, que analisei com mais detalhe em outra parte (Bolaño e Silva, 2005).

O fundamental é saber que, para Marx, a definição de uma Revolução Industrial passa necessariamente pela expansão da subsunção do trabalho no capital: a passagem da subsunção formal à real, na primeira, e a mesma passagem para o setor produtor das próprias máquinas, na segunda, conforme explicita no capítulo 13, ao falar da "produção de máquinas por meio de máquinas”. Minha própria hipótese sobre a subsunção do trabalho intelectual segue a mesma linha de pensamento, definindo a Terceira Revolução Industrial - na esteira das transformações sociológicas trazidas pelo desenvolvimento do Capitalismo Monopolista, ao longo do século XX, que levarão à constituição de uma camada média de trabalhadores intelectuais dispondo de uma importante autonomia relativa no processo de trabalho, no interior da grande empresa - como aquele momento em que essa autonomia relativa será rompida.

Na verdade, a hipótese se refere à subsunção do trabalho intelectual e a uma extensa intelectualização de todos os processos de trabalho convencionais e do consumo, de modo que é ao conjunto do modo de regulação, digamos assim, a que me refiro. Mais ainda, tendo em vista que a separação original entre trabalho manual e intelectual se dá na 
Grécia Antiga, conforme explicita Sohn-Rethel, as promessas de reconciliação abertas pelo capital (que de fato já as reunificara, desde o início e de forma progressiva, no seu interior), mas que o próprio capital não cumpre, apontam para possibilidades inéditas de liberação, no sentido daquilo que alguns acreditam ter visto realizado sob o próprio capital, com base em uma leitura parcial do mencionado trecho dos Grundrisse sobre o intelecto geral.

Ao contrário, seguindo a nossa linha de raciocínio, é possível formular rigorosamente, no sentido de Marx, a questão mal concebida pelos teóricos do imaterial e do chamado capitalismo cognitivo. Em primeiro lugar, é importante enfatizar a importância e centralidade do conceito de subsunção que, em Marx, ao contrário de Negri, se refere à incorporação do trabalho no capital como elemento subordinado que mantém, não obstante, a sua identidade no interior daquela unidade maior.

A subsunção formal, forma geral de toda subsunção, ocorre sempre que se estabelece a relação salarial, ou seja, quando o capitalista adquire a força de trabalho e, com isso, o direito de explorá-la e de apropriar-se de todo o resultado do processo de trabalho que, no entanto, permanece, durante todo o período manufatureiro, na dependência do conhecimento e das habilidades do trabalhador individual na utilização das ferramentas herdadas do artesanato. Apenas com a Revolução Industrial, o capital se libertará dessa dependência, subsumindo realmente o trabalho através da máquina ferramenta, que inverte a relação sujeitoobjeto, com os elementos do capital constante (máquinas, instrumentos de trabalho) definindo, a partir de então, a forma e o ritmo do processo de trabalho.

O princípio de tudo, em todo caso, é a cooperação entre a massa dos trabalhadores subordinados à direção de um mesmo capital. $\mathrm{O}$ caráter contraditório e crítico da relação de capital se estabelece justamente pelo fato de que essa massa operária, posta assim a cooperar pelo capital e a seu serviço, pode passar, num dado momento, a cooperar entre si, contra o sistema de exploração do capital.

A especificidade da situação atual é que a socialização da produção superou todos os limites, organizando-se, no que se refere à produção final da mercadoria, em torno de pequenos coletivos de trabalhadores altamente qualificados - articulados em nível global, via telemática, controlando unidades produtivas totalmente automatizadas, robotizadas, flexíveis -, que obedecem às determinações superiores da produção de conhecimento prévia, dependente, esta, da existência de vastas esferas públicas produtivas em que o trabalho intelectual se socializa. Sem essas esferas de comunicação produtiva, aquele trabalhador intelectual não pode operar. Por outro lado, embora a sua produtividade para o capital seja inegável, ela é inquantificável do ponto de vista 
dos trabalhadores individuais e a apropriação privada, pelo capital, do resultado dessa produção social de riqueza só será possível através do tour de force dos direitos de propriedade intelectual (Bolaño, 2003).

Assim, a subsunção do trabalho intelectual representa um avanço no sistema de controle do capital sobre o trabalho, que, ao radicalizar a contradição entre socialização da produção e apropriação privada, coloca em primeiro plano a possibilidade de superação do capitalismo no sentido originalmente proposto por Marx.

\section{Intelecto geral}

A questão está ligada, evidentemente, à evolução da relação entre ciência e indústria, que solapa os fundamentos do capitalismo industrial observado por Marx no seu momento. Mas o próprio Marx havia deduzido essa possibilidade, colocando a questão em termos absolutamente atuais para os dias de hoje, nos trechos dos Grundrisse acima referidos, que se encontram, em sua maior parte, sob um subtítulo bastante sugestivo: "contradição entre a base da produção burguesa (medida do valor) e seu próprio desenvolvimento..." (Marx 1857-1858, vol. 2:227). É preciso cita-los extensamente.

El intercambio de trabajo vivo por trabajo objetivado, es decir el poner el trabajo social bajo la forma de la antítesis entre el capital y el trabajo, es el último desarrollo de la relación de valor y de la producción fundada en el valor. El supuesto de esta producción es, y sigue siendo, la magnitud de tiempo inmediato de trabajo, el cuanto de trabajo empleado como el factor decisivo en la producción de la riqueza. En la medida, sin embargo, en que la gran industria se desarrolla, la creación de la riqueza efectiva se vuelve menos dependiente del tiempo de trabajo y del cuanto de trabajo empleados, que del poder de los agentes puestos en movimiento durante el tiempo de trabajo, poder que a su vez - su powerful effectiveness - no guarda relación alguna con el tiempo de trabajo inmediato que cuesta su producción, sino que depende más bien del estado general de la ciencia y del progreso de la tecnología, o de la aplicación de esta ciencia a la producción. (Marx 1857-1858, vol. 2: 227-8). ${ }^{3}$

Antes de tirarmos conclusões gerais, vale notar que meu próprio trabalho sobre os processos de produção de conhecimento na área da genômica confirma a idéia, já mencionada, de impossibilidade de quantificação do valor incorporado em uma mercadoria (um bem, como

3 Neste ponto, acrescenta, entre parênteses: "el desarrollo de esta ciencia, esencialmente de la ciencia natural y con ella de todas las demás, está a su vez en relación con el desarrollo de la producción material" (Marx 1857-1858, vol. 2:228). 
uma droga, ou serviço, como um procedimento médico) final que inclui conhecimento produzido ao longo de uma cadeia produtiva muito extensa e segmentada, em que boa parte do trabalho obedece à lógica acadêmica da produção científica certificada, oposta, por princípio, à lógica capitalista e financiada em geral com fundo público (Bolaño 2003). Não se trata simplesmente de incorporação do conhecimento científico à produção da mercadoria, mas da subsunção no capital, do conjunto da produção científica, nessa área específica, o que só é possível - dada a contradição inerente a uma lógica a uma vez industrial e acadêmica através da subordinação do conjunto à lógica hegemônica do capital fictício, isto é, de uma economia, em última instância, não propriamente industrial, nem pós-industrial, mas fundamentalmente especulativa e rentista, em que a distribuição do produto depende da arbitrariedade dos direitos de propriedade intelectual.

Tomo o cuidado de não generalizar ainda a conclusão, enfatizando que estamos tratando de uma área específica da produção intelectual, não apenas porque a chamada economia do conhecimento não abarca ainda toda a produção capitalista, mas sobretudo porque é importante evitar a ilusão fetichista da conceituação abstrata de um conhecimento capaz de dissolver as contradições inerentes ao capitalismo, ou resolvê-las a favor de uma emancipação humana também em abstrato. ${ }^{4}$ Mas prossigamos na leitura:

La riqueza efectiva se manifiesta más bien - y esto lo revela la gran industria - en la enorme desproporción entre el tiempo de trabajo empleado y su producto, así como en la desproporción cualitativa entre ele trabajo, reducido a una pura abstracción y el poderío del proceso de producción vigilado por aquél (Marx 1857-1858, vol. 2:228).

Note-se que o autor se refere a uma situação, comum nos dias de hoje, em que o trabalhador tem por função primordial, vigiar a produção automatizada. É isso o que acontece, de fato, com a automatização na indústria, permitida pela robotização, as máquinas ferramenta de controle numérico etc. Assim,

el trabajo ya no aparece tanto como recluido en el proceso de producción, sino que más bien el hombre se comporta como supervisor y regulador con respecto al proceso de producción mismo. El trabajador ya no introduce el objeto natural modificado, como el eslabón intermedio, entre la cosa y sí mismo, sino que inserta el proceso natural, al que transforma en industrial, como medio entre sí mismo y la naturaleza inorgánica, a la que domina. Se presenta al lado del proceso de producción, en lugar de ser su agente principal (idem). 
BOLAÑO, C. Sobre intelecto geral, capital, comunicação e conhecimento: uma leitura...

Trata-se, em essência, de um processo de trabalho tipicamente industrial, em que o componente científico de que falei ao citar o caso da pesquisa genômica não está posto propriamente, mas pressuposto:

En esta transformación lo que aparece como el pilar fundamental de la producción y de la riqueza no es ni el trabajo inmediato ejecutado por el hombre ni el tiempo que éste trabaja, sino la apropiación de su propia fuerza productiva general, su comprensión de la naturaleza y su dominio de la misma gracias a su existencia como cuerpo social; en una palabra, el desarrollo del individuo social (idem).

Ou seja, voltando ao nosso exemplo da genômica, o que aparece como pilar fundamental da produção da riqueza não é nem o trabalho imediato executado, digamos, pelos trabalhadores da indústria farmacêutica que produzem uma determinada droga, nem o tempo em que estes trabalham, mas a apropriação da força produtiva geral da indústria farmacêutica e da indústria do conhecimento vinculada àquela longa cadeia produtiva, a compreensão da natureza desse conjunto de trabalhadores que, inseridos em diferentes empresas e instituições, possuem um domínio sobre ela que só pode ser social e ultrapassa em muito os limites do capital individual que efetivamente se apropriará, com base em patentes, da riqueza produzida por esse "individuo social". É nessas condições que

El robo de tiempo de trabajo ajeno, sobre el cual se funda la riqueza actual aparece como una base miserable comparado con este fundamento, recién desarrollado, creado por la gran industria misma (idem).

Até aqui nos trouxe a grande indústria. Esta é a encruzilhada do capitalismo do início do século XXI. Marx teve a clarividência de prevê-la e, em seguida, tratará de explorar as conseqüências possíveis da situação. Logo na seqüência do último trecho citado, afirma que "tan pronto como el trabajo en su forma inmediata deja de ser la gran fuente de la riqueza, el tiempo de trabajo deja, y tiene que dejar, de ser su medida y por tanto el valor de cambio [deja de ser la medida] del valor de uso" (idem). Note-se que o texto foi escrito nos anos 50 do século XIX e que, portanto, o que afirma, em bom português é que "quando o trabalho, na sua forma imediata, deixar de ser a grande fonte de riqueza", ou seja, quando a grande fonte de riqueza passar a ser, na nossa leitura, o trabalho intelectual, na sua forma imediata, de trabalho científico acadêmico subsumido no capital nos termos acima referidos, como trabalho social de valor inquantificável, então o tempo de trabalho terá que deixar de ser a sua medida e o valor de troca deixará de ser a medida do valor de uso, colocando em xeque a própria teoria do valor. 
Nessas condições, "el plustrabajo de la masa ha dejado [ou terá deixado] de ser condición para el desarrollo de la riqueza social, así como el no-trabajo de unos pocos ha cesado [ou terá cessado] de serlo para el desarrollo de los poderes generales del intelecto humano" (idem, p. 2289). Estaríamos, portanto, frente à falência da exploração capitalista do trabalho e à perspectiva concreta, iminente, de sua superação:

Con ello se desploma la producción fundada en el valor de cambio, y al proceso de producción material inmediato se le quita la forma de la necesidad apremiante y el antagonismo. Desarrollo libre de las individualidades, y por ende no reducción del tiempo de trabajo necesario con miras a poner plustrabajo, sino en general reducción del tiempo de trabajo necesario de la sociedad a un mínimo, al cual corresponde entonces la formación artística, científica, etc., de los individuos gracias al tiempo que se ha vuelto libre y a los medios creados para todos (idem).

É claro que este último resultado não poderá concretizar-se, na perspectiva de Marx, pelo simples desenvolvimento das forças produtivas, sem a ação consciente do fator subjetivo que possibilitaria a passagem para uma organização superior da sociedade humana. Mas, para ele, são as próprias contradições inerentes ao desenvolvimento capitalista que abrirão caminho para essa passagem:

El capital mismo es la contradicción en proceso, [por el hecho de] que tiende a reducir a un mínimo el tiempo de trabajo, mientras que por otra parte pone al tiempo de trabajo como única medida y fuente de la riqueza. Disminuye, pues, el tiempo de trabajo en la forma de tiempo de trabajo necesario, para aumentarlo en la forma del trabajo excedente; pone por tanto, en medida creciente, el trabajo excedente como condición - question de vie et de mort - del necesario. Por un lado despierta a la vida todos los poderes de la ciencia y de la naturaleza, así como de la cooperación y del intercambio sociales, para hacer que la creación de la riqueza sea (relativamente) independiente del tiempo de trabajo empleado en ella. Por el otro lado se propone medir con el tiempo de trabajo esas gigantescas fuerzas sociales creadas de esta suerte y reducirlas a los límites requeridos para que el valor ya creado se conserve como valor. Las fuerzas productivas y las relaciones sociales - unas y otras aspectos diversos del desarrollo del individuo social - se le aparecen al capital únicamente como medios para producir fundándose en su mezquina base. In fact, empero, constituyen las condiciones materiales para hacer saltar a esa base por los aires" (idem).

Assim, o capital, essa contradição em processo, desenvolve as condições materiais para a sua própria superação, o que dependerá, ao final, das condições espirituais, subjetivas que se venham a desenvolver sobre essa base material transformada. Há aí dois problemas de que o próprio Marx não poderia tratar naquele momento. Em primeiro lugar, 
e ele deixa isto muito claro no último trecho citado, forças produtivas e relações sociais de produção são dois aspectos diferentes do desenvolvimento do individuo social e não seria possível, a meados do século XIX, imaginar o resultado concreto a que só se chegou na transição do século XX para o XXI, em conseqüência de uma tendência, própria da fase monopolista do capitalismo, de expansão das camadas médias assalariadas, cujo trabalho vai-se tornando progressivamente produtivo e que formará a base para o atual processo de subsunção do trabalho intelectual de que falei acima.

Nem Marx, nem as ortodoxias marxistas da segunda e da terceira internacionais puderam antever esse movimento. Ao contrário, se voltarmos à leitura do problema da subsunção do trabalho, no capítulo 13 do Livro Primeiro d'O capital, observaremos que, aparentemente, para o autor, a "produção de máquinas por meio de máquinas" concluiria a passagem da subsunção formal à real, de forma definitiva. No Capítulo Sexto Inédito, por sua vez, embora a problemática da produtividade do trabalho cultural e intelectual seja posta nos seus termos mais justos, Marx não dá importância ao fenômeno, considerando-o, como de fato era naquele momento, estatisticamente irrelevante.

É por isso que, nos trechos acima citados, a subsunção da ciência não chega a ser posta em nenhum momento em termos de subsunção do trabalho científico no capital e o autor procede em diferentes ocasiões à generalização que eu procurei explicitamente evitar. É certo que essa generalização é legítima, pois ele se move no nível das leis gerais imanentes da produção capitalista, mas isso não elimina, antes pelo contrário, o problema com que se defronta a nossa própria geração - de especificar justamente o movimento concreto da subsunção da ciência - nem muito menos justifica que, da nossa parte, reproduzamos, à l'aise, a mesma generalização, tomando-a como um dogma, para oferecer uma explicação ideológica da realidade atual.

Em segundo lugar, é preciso deixar claro que - não sendo a transformação progressiva do sistema, decorrência direta do puro desenvolvimento das forças produtivas -, enquanto as relações de produção não forem transformadas (pela ação do novo fator subjetivo que nos cabe especificar), o sistema entrará em uma dinâmica regressiva de exclusão e violência crescentes, colocando na ordem do dia, a velha disjuntiva, socialismo ou barbárie. Este é precisamente o ponto em que nos encontramos hoje. Mas voltemos ao texto de Marx:

La naturaleza no construye máquinas, ni locomotoras, ferrocarriles, electric telegraphs, selfacting mules, etc. Son éstos, productos de la industria humana; material natural, transformado en órganos de la voluntad humana sobre la naturaleza o de su actuación sobre la naturaleza. Son órganos del cerebro humano creados por la mano 
humana; fuerza objetivada del conocimiento. El desarrollo del capital fixe revela hasta qué punto el conocimiento o knowledge social general se ha convertido en la fuerza productiva inmediata, y, por lo tanto, hasta qué punto las condiciones del proceso de la vida social misma han entrado bajo los controles del general intellect y remodeladas conforme al mismo. Hasta qué punto las fuerzas productivas sociales son producidas no sólo en la forma del conocimiento, sino como órganos inmediatos de la práctica social, del proceso vital real.

(idem:229-30)

Note-se que aqui a ciência se torna força produtiva imediata. É subsumida, podemos dizer. Com isso Marx conclui o trecho em exame, retomando o eixo central da análise das relações entre capital fixo e circulante. Não poderemos voltar, evidentemente, a essa discussão, mas vale lembrar que o parágrafo imediatamente posterior a este último citado explicita o caráter contraditório do processo, pois o desenvolvimento do capital fixo mostra não apenas até que ponto as condições do processo da própria vida social se submetem aos controles do intelecto geral, mas também que, "desde otro punto de vista, el grado de desarrollo alcanzado por la riqueza en general o del desarrollo del capital" (idem:230), ou seja, em que medida esse general intellect está subsumido no capital:

La parte de la producción orientada hacia la producción del capital fixe no produce directamente objetos de disfrute, ni tampoco valores de cambio inmediatos; por lo menos no produce valores de cambio realizables de manera inmediata. Por lo tanto, que se emplee una parte cada vez mayor del tiempo de producción para producir medios de producción, depende del grado de productividad ya alcanzado, de que una parte del tiempo de producción baste para la producción inmediata. Ello implica que la sociedad puede esperar; que una gran parte de la riqueza ya creada puede desviarla del disfrute inmediato como de la producción destinada al disfrute inmediato con vistas a emplearla en un trabajo no directamente productivo (dentro del proceso mismo de producción). Esto requiere que se haya alcanzado ya un alto nivel de productividad y una abundancia relativa, y precisamente tal nivel en relación directa con la transformación del capital circulant en capital fixe (idem:230-1).

Nessas condições, a sociedade pode criar, como tratará de explicar o autor em seguida, um tempo de não trabalho que se afigura como contradição pois o capital, "malgré lui, es instrumental in crreating the means of social disposable time, para reducir a un mínimo decreciente el tiempo de trabajo de toda la sociedad y así, volver libre el tiempo de todos para el propio desarrollo de los mismos. Su tendencia, empero, es siempre por un lado la de crear disposable time, por otro la de to convert it into surplus labour" (idem:231-2). 
Para além do fato de que, ao mesmo tempo em que cria as condições do não trabalho, o capital "aumenta el tiempo de plustrabajo de la masa mediante todos los recursos del arte y de la ciencia”, essa questão do tempo livre e da sua manipulação pelo capital está na base evidentemente do desenvolvimento, durante o século XX, da Indústria Cultural (Bolaño, 2000) e Marx de alguma forma o intui, ao mostrar que a economia do tempo de trabalho se relaciona com o desenvolvimento da força produtiva e não com a abstinência do desfrute que, ao contrário, é condição para o desenvolvimento da produção. Assim, "capacidad de disfrute ... equivale a desarrollo de una aptitud individual, fuerza productiva. El ahorro del tiempo de trabajo corre parejas con el aumento del tiempo libre, o sea tiempo para el desarrollo pleno del individuo, desenvolvimiento que a su vez re-actúa como máxima fuerza productiva sobre la fuerza productiva del trabajo" (Marx 1857-1858, vol. 2:231).

A boa interpretação desse trecho poderia ser feita com base, de um lado, na retomada da discussão sobre as relações entre produção e consumo, tal como explicitadas na Introdução à Crítica da Economia Política, adaptando-a para a análise da produção cultural, segundo o referencial teórico de corte marxiano presente, por exemplo, em Bolaño (2000). Terei enorme prazer em fazê-lo em outra ocasião, visto que, com isso, será possível esclarecer uma série de dificuldades presentes em boa parte das Teorias da Comunicação que desconhecem completamente o problema. Neste texto, no entanto, o único interesse em citar este trecho tem a ver com a sua continuidade: "se puede considerar a ese ahorro, desde el punto de vista del proceso inmediato de producción, como producción de capital fixe, este capital fixe being man himself' (idem).

André Gorz utilizará essa frase para afirmar que "a idéia de "capital humano' se encontra, pois, já nos manuscritos de 1857-1858" (Gorz, 2003, p. 16). Eleutério Prado nota bem o caráter fetichista dessa dedução, observando que a observação de Marx é feita, no trecho citado, "do ponto de vista imediato do processo de produção". Vale citar:

se, pois, o homem é apreendido como capital, pode-se falar do homem
como conteúdo corporal e espiritual do capital (...) mas não se pode
dizer que o capital é humano (...) Assim, não se pode dizer também (...)
que o homem é capital. Pois, nesse segundo caso, a matéria do capital,
ou seja, a matéria humana, é identificada com o próprio capital,
chegando a figurar, no texto de Gorz, como 'pleno desenvolvimento do
indivíduo' (Prado 2005:77).

E, mais adiante: "o conceito de capital humano adquire proeminência na prática e no imaginário social ... quando o fetiche do sistema de máquinas como capital é gradativamente substituído pelo fetiche do traba- 
lhador produtor de valores de uso ditos imateriais como capital" (idem:78). Quando o capitalista individual investe na formação do trabalhador, "essa força de trabalho melhorada em sua competência produtiva ... parece pertencer-lhe não apenas como algo que ele emprega por certo período e que usa até certo ponto, mas como capital fixo da empresa" (idem:78-9). Assim, ao invés de aumentar o salário do trabalhador, o capitalista investe uma parte do seu capital variável (não do constante) na formação do trabalhador, com o que obtém uma dupla vantagem: "primeiro, faz com que esse gasto pareça uma concessão e um benefício voluntário que ele dá àqueles que emprega e, segundo, ele orienta o gasto destes últimos no seu próprio interesse de capitalista" (idem:79). Mesmo no caso em que os gastos com educação e treinamento sejam realizados pelo Estado,

\begin{abstract}
a força de trabalho se afigura 'do ponto de vista do processo de produção imediato' e, assim, também do capitalista aparentemente benemerente, como capital fixo que pertence à empresa - não, entretanto, num sentido forte. Pois, mesmo nesse caso, esse 'capital fixo' é encarado como virtual pelo empreendimento capitalista. Ele não é, e não pode ser, sua propriedade integral; ademais ele não pode também ser depreciado tal como o capital fixo verdadeiro que pertence à empresa (...) Apenas pode ser incorporado ao valor da mercadoria por meio da criação de valor novo ... num processo que, como se sabe, reproduz o custo da força de trabalho e gera mais-valia. "Tem-se, assim, um 'capital fixo' que nada mais é do que uma transfiguração do capital variável” (idem:79)
\end{abstract}

Mas o fundamental, para nossos interesses, reside na referida contradição inerente à existência daquele tempo livre, a qual, quanto mais desenvolvida, "tanto más evidente se hace que el crecimiento de las fuerzas productivas ya no puede estar ligado a la apropiación de surplus labour ajeno, sino que la masa obrera misma debe apropiarse de su plustrabajo" (Marx 1857-1858, vol. 2:232). O que ocorreria, então, se essa contradição se resolve a favor da classe trabalhadora? Resposta:

Una vez que lo logra - y con ello el disposable time dejará de tener una existencia antitética - por una parte el tiempo de trabajo necesario encontrará su medida en las necesidades del individuo social y por otra el desarrollo de la fuerza productiva social será tan rápido que, aunque ahora la producción se calcula en función de la riqueza común, crecerá el disposable time de todos. Ya que la riqueza real es la fuerza productiva desarrollada de todos los individuos. Ya no es entonces, en modo alguno, el tiempo de trabajo la medida de la riqueza, sino el disposable time (idem). 
BOLAÑO, C. Sobre intelecto geral, capital, comunicação e conhecimento: uma leitura...

Isso não é possível no capitalismo, por mais avançadas que sejam as forças produtivas:

\begin{abstract}
El tiempo de trabajo como medida de la riqueza pone la riqueza misma como fundada en la pobreza y al disposable time como existente en y en virtud de la antítesis con el tiempo de plustrabajo, o bien pone todo el tiempo de un individuo como tiempo de trabajo y consiguientemente lo degrada a mero trabajador, lo subsume en el trabajo. La maquinaria más desarrollada, pues, compele actualmente al obrero a trabajar más tiempo que el que trabaja el salvaje o que el que trabajaría el mismo con las herramientas más sencillas y toscas (idem).
\end{abstract}

Esse é o sentido de todo o desenvolvimento tecnológico submetido à lógica do capital e assim continua sendo nos dias de hoje. O desenvolvimento da micro-eletrônica e da informática, especialmente do uso generalizado do computador como instrumento de trabalho e de laser, deixa isso muito explícito e aqui estamos em uma situação ainda mais radical do que aquela da velha Indústria Cultural do século XX - que de resto permanece firme e forte como forma de dominação ideológica e de publicidade.

Mas justamente neste momento, em que o capital se vale efetivamente de todos os poderes da arte e da ciência para aumentar a exploração e preservar o seu sistema de poder, pode-se entrever as condições se gestando para o surgimento de um mundo novo. "Así como el sistema de la economía burguesa para nosotros se ha desarrollado tan sólo poco a poco, otro tanto ocurre con la negación del sistema mismo, negación que es resultado último de esa economía" (idem:237).

\title{
Referências
}

BOLAÑO, César (1995). "Economia Política, Globalización y Comunicación." In: Nueva Sociedad, $\mathrm{n}^{\circ} 140$, Caracas.

BOLAÑO, César (2000). Indústria Cultural, Informação e Capitalismo. São Paulo: HUCITEC.

BOLAÑO, César (2002). "Trabalho intelectual, comunicação e capitalismo." In: Revista da Sociedade Brasileira de Economia Política, Rio de Janeiro, n. 11, dez., p. 53-78.

BOLAÑO, César (2002b). Impactos sociais e econômicos das tecnologias da informação e da comunicação. Hipóteses sobre a atual reestruturação capitalista. In: Conexão, vol. 1, n. 2, jul. dez./2002, USC, Caxias do Sul, p. 143-153.

BOLAÑO, César (2003). "Economia Política do Conhecimento e o Projeto Genoma Humano do Câncer de São Paulo.” In: CD-Rom ANCIB. Belo Horizonte. 
BOLAÑO, C. \& HERSCOVICI, A. (2005). “A Crítica da Economia Política da Informação e do Conhecimento.” In: CD-Rom do Congresso da SEP, Campinas.

BOLAÑO, C. \& SILVA, L. (2005). “Trabalho Médico e Capitalismo: Uma introdução à Economia Política dos Serviços de Saúde." In: Atas do Congresso da Sociedade Brasileira de Economia Política - SEP 2005 Campinas: UNICAMP.

BOLAÑO, C. \& MATTOS, F. (2004). "Conhecimento e Informação na atual Reestruturação Produtiva: para uma crítica das teorias da Gestão do Conhecimento." Datagramazero. Revista de Ciência da Informação, vol. 5, n. 3, junho. Rio de Janeiro. Disponível em: www.dgz.org.br.

FAUSTO, Ruy (1987). Marx: lógica e política - vol. II. São Paulo: Brasiliense.

FAUSTO, Ruy (2002). Marx: lógica e política - vol. III. São Paulo: Brasiliense.

GORZ, André (2003). O imaterial. Conhecimento, valor e capital. São Paulo: Annablume, 2005 .

HABERMAS, Jürgen (1961). Mudança estrutural da esfera pública. Rio de Janeiro: Tempo Brasileiro, 1984.

LOJKINE, Jean (1995). A Revolução Informacional. Ed. Cortez.

MARX, Karl (1857-1858). Elementos Fundamentales para la crítica de la economía política. México: Siglo XXI, 1980.

MARX, Karl (1980) [1867]. O Capital. Crítica da Economia Política. Rio de Janeiro: Civilização Brasileira.

PRADO, Eleutério (2005). Desmedida do valor. Crítica da pós-grande indústria. São Paulo: Xamã.

SOHN-RETHEL, Alfred (1989). Trabalho Espiritual e Corporal Para a Epistemologia da História Ocidental. UFPB/CCSA, Mestrado em Economia, 1995 . 